\title{
DNA Repair Pathway
}

National Cancer Institute

\section{Source}

National Cancer Institute. DNA Repair Pathway. NCI Thesaurus. Code C39705.

A sequence of biological or biochemical events that play a role in DNA repair. 